\title{
Designing Movement, Modulating Mood
}

Sarah Robinson

Abstract: This article illustrates how the isomorphism between bodily form and emotional expression is manifest in architectural experience through applying research findings in the fields of cognitive science, phenomenology, and psychology to practical examples in the work of Aldo van Eyck, Alvar Aalto, Rosan Bosch, Herman Hertzberger, Steen Eiler-Rasmussen, and Gaston Bachelard. Beginning with the micro-scale movement in facial expressions to larger scale patterns of collective movement and mood, this work understands architecture in its activeverbal form, as a patterning force capable of modulating rhythms and resonances at individual and societal scales of interaction.

Keywords: Resonance; Rhythm; Emotion-Gesture Isomorphism; Entrainment; Counterform; Counter Muscle; Mood Modulation.

»The gesture does not make me think of anger, it is anger itself.« Maurice Merleau-Ponty (2002: 214)

Joy is a feeling of levity, buoyancy - an effortless floating on the currents of life. Sadness feels heavy and compressing - a sapping of energy. Joy expands, while sadness contracts. Feeling joy not only enlarges one's sense of possibility, feeling joyful opens the chest and loosens arms and hands. When we are sad, our slumped shoulders and head outwardly express our internalization. Happiness broadens our face and arches our lips upward, while anger tightens the jaw and clenches the fist. The word emotion - e-motion - has motion built into its very name. Emotion and its expression seem to share an isomorphic congruency. Form and feeling match. »It is difficult to feel intimacy while shouting, to rage in a low whisper, to skip and weep at the same time«, wrote the poet Jane Hirschfield (Hirschfield 1997: 54). Indeed, each of these gestures seem to have their own inherent emotional signature. Charles Darwin was the first to conduct experimental research 
on just this question. In his lesser-known work, The Expression of Emotions in Man and Animals (Darwin 1872), Darwin argued that emotional gestures are shared not only across cultures but throughout the animal world, and are not exclusive to humans. The basic findings of this early work have since been corroborated and it is now widely accepted among psychologists that certain emotions - such as anger, sadness, fear, surprise, disgust, happiness, and contempt can be considered universal. When the psychologist Paul Ekman and his colleagues studied the facial expressions of these basic emotions, they discovered that each one is linked with a distinct facial expression that was remarkably congruent across widely diverse cultures (Ekman 1993).

What is more, each of these emotions has a gestural corollary that is not asymmetric. That is, not only is the emotion expressed outwardly in a consistent bodily gesture or posture, assuming that specific posture reciprocally evokes that emotion. Smiling is not only the outward expression of feeling happy - engaging the musculature of smiling causes hormonal shifts that relieve pain, reduce stress, and has the same effect as anti-depressants - it also has the physiological signature of feeling happy (Adelmann/Zajonc 1989). Furthermore, the effects of smiling are not limited to the individual smiling causes others to smile as well (Dimberg/Söderkvist 2011). This facial feedback has been shown to both modulate and initiate emotions for both happiness and anger, and is also involved in the emotions of surprise and disgust (Lewis 2012).

\section{Emotion-Gesture Isomorphism}

While the face is the bodily region sui generis of this isomorphism between emotion and gesture, this congruency has also been shown to be consistent in bodily postures. Returning to the poetic insight that opened this essay why is feeling down often accompanied with leaning down? Experimental research indicates that bodily postures do indeed directly impact emotional processes. People who smile while adopting an upright posture are able to remember positive memories more readily (Riskind 1984). Whereas sitting in a stooped position while imagining an event leads people to recall more negative associations (Michalak/Mischnat/Teisman 2014). Assuming a stooped posture is also connected to feeling a diminished sense of pride (Stepper/ Strack 1993) and helplessness (Riskind/Gotay 1982). While an upright body posture, on the other hand, enables people to recover quickly from negative 
feelings and correlates to feelings of empowerment (Carney/Cuddy/Yap 2010) and pride (Oosterwijk et al. 2009).

Posture also plays an important role in recovering from a negative mood and modulates negative feelings (Veenstra/Schneider/Koole 2017). Posture corresponds not only with emotional states but also with cognitive performance. An experiment with Japanese school children found that upright posture increased vitality and pleasure, as well as heart rate, symptomatic of increased vitality, compared with normal posture, and that upright posture also led to significantly higher scores for calculation and listening comprehension tests (Inagaki et al. 2018). This work strongly indicates that assuming an upright posture contributes to maintaining a positive psychological state and improving children's performance in tests.

The isomorphic congruency between emotion and gesture, the very fact that an angry scowl is not a gesture of anger, but anger itself, as MerleauPonty insisted, takes us far from traditional theories that understood emotion as a subjective internal state (Merleau-Ponty 2002). According to John Dewey, not only is emotion not the sole possession of the individual emotion belongs to the broader context in which the individual is situated. So, in a threatening situation, rather than saying that »I am fearful«, it would be more accurate to say that the »situation is fearful« (Johnson 2015: 43). For Dewey, emotions were not »reactions in the head« (Dewey 1934: 72), but a kind of shared situated resonance. Fear, in this case, is an emergent response to an actual situation - an eruption in the fluid dynamic in which both organism and event are embedded. The »concrete whole « of emotional experience is comprised of the internally experienced neural and physiological responses together with the situational processes in their complex interaction. Far from being confused thoughts that needed to be suppressed, Dewey argued that emotion is the basis of rational thought and meaningful action and that its healthy expression is critical to individual and cultural creation and equilibrium.

\section{Counterforms}

Taking emotion out of the head and into the body and world must be a welcome development for designers - it proves that what we make matters. In creating the concrete situations of daily life, we mold the posture, invite gestures, and orchestrate the movement of countless bodies. And in doing so, we have the power to shift the emotional state and influence the mental 
outlook and cognitive abilities of those who inhabit the places we make. Yet to fully appreciate these possibilities requires a thorough rethinking of form. Form, as I have insisted elsewhere (Robinson 2021), must be considered in its verbal sense. Form forms. Instead of thinking about design in terms of what it looks like in a passive sense, one must develop the knowledge of what design can do in an active sense. What actions, thoughts, and feelings might design activate?

This understanding resonates with the way in which Aldo van Eyck understood form. He insisted that the architect's task is to build the counterform to human action - and imagined this relationship as the shell is to the mollusk. The shell, while apparently solid is extruded from the force, pressure, and movement of the body. He referred to this innate reciprocity between body/ form/action as a perpetual homecoming. What if we imagine this dynamic interaction as analogous to the way that a smile is the counterform to happiness, or a whisper is the counterform to intimacy, or the actions of skipping and laughing are the counterforms to joy? Perhaps we might find a way to create forms that share this same isomorphic congruency. Smiling, whispering, skipping, and laughing not only express happiness, intimacy, and joy - they also loop back to generate those particular emotions and feelings.

One example to consider in this direction is Alvar Aalto's iconic chair for the Paimio Sanatorium, a hospital dedicated to those who suffered from tuberculosis. While, at the time of its construction in 1930, sunlight and fresh air were the only known cures, the Paimio chairs' sinuous curves were not designed for how they looked, but for what they did. The curves were specifically designed to open the chest and ease breathing. Aalto was inspired by Marcel Breuer's Wassily chair, but intentionally eschewed tubular steel because it conducts heat away from the body. Instead, Aalto pioneered curved plywood - a most humane material that is porous and breathes like human skin. The chair is gorgeously sensuous, but its aesthetic appeal was not its main objective but a consequence of its success as a counterform that affords the healing process. The chair is not an object, but an instrument for healing, and its form is an outward expression of relaxed breathing, just as the smile is an outward expression of happiness. The chair was intended to be an instrument of healing nested within in a larger series of instruments: the chairs were assembled in a sunlit room with fellow patients, the sunlit room was nested in a strategically positioned building, which was in turn nested in a forest for an integrated curative whole. 
While the Paimio chair was designed for a specific purpose - Aldo van Eyck insisted on designing counterforms that were at once specific and open-ended. He was particularly sensitive to the shifting needs of children's developing bodies and the entire orphanage complex he designed in Amsterdam exemplifies his remarkable sense of care and accommodation for the changing physical and psychological needs of children. Each age group had its own space structured according to their emerging capacities and skills. At the center of the area for infants to two year olds, for example, sat a three-tiered raised platform that echoed the shape of the circular room in which it was placed. A railing encircled the outer edge of this area and the whole was crowned with a single dome. The central »hilltop« provided an opportunity for very young children to crawl up and practice standing, while the adjacent railing served as an ideal support for their first tentative steps. The building itself became an active partner in the adventure of learning how to walk and concretely empowered the children's newfound sense of verticality.

From this room, the circular sandpit for the two to four year olds is visible in the courtyard. Four benches are situated in a pinwheel pattern so that adults can observe the children without impinging on their exploratory activities. From their position within the sandpit, the children can see the play hill from which they recently graduated. These visual relationships lend a reassuring sense of continuity and security. The sandpit for four to six year olds was set in a smaller raised platform whose bowl-shaped circular recesses collected rainwater to become splash pools and mirrors reflecting the sky, and because children desire more independence at this age, the encompassing benches were intentionally left out. Van Eyck's celebrated "play pool alias seat « as he called it (McCarter 2015: 110), is located at the seam between the indoor and outdoor spaces. On one side, the children felt a sense of shelter, while on the other, a sense of openness - which subtly appeals to the oscillating tension between the need for adventure and the need for retreat. The shallow pool is filled with water and encircled by a bench so that the children can dangle their legs and splash their feet with a sense of abandon. The bench has concrete backrests interspersed with pink glass. In the sunlight, bright pink reflections shimmer simultaneously on the surface of the water and on the ceiling above. This multi-dimensional dance of light and color is a counterform to the magical act of play in a place perfectly fit for the needs of the children, at once a place of protection, mischief, and delight. 


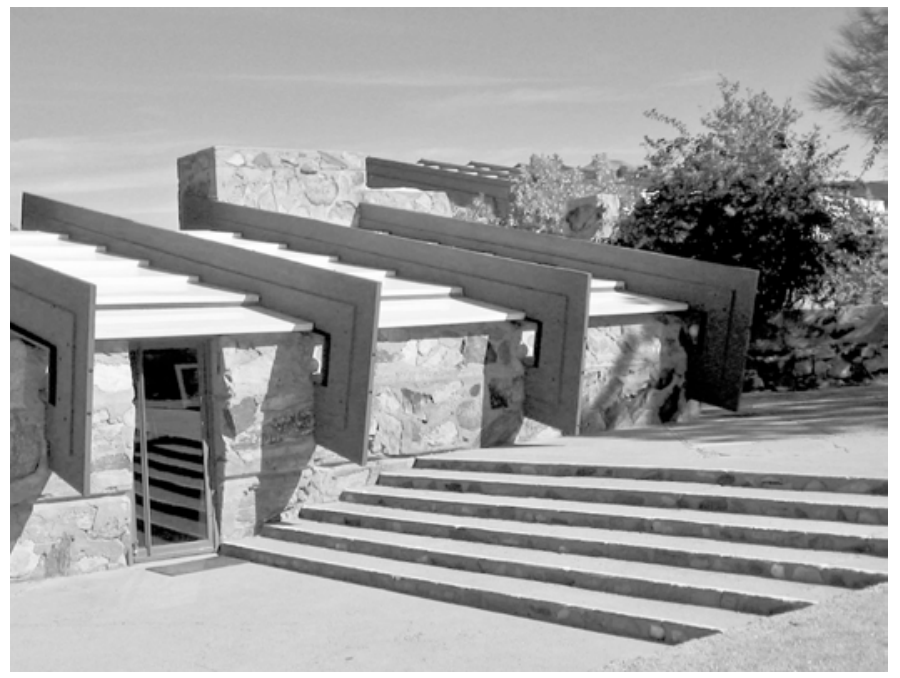

1.

Frank Lloyd Wright: Taliesin West, 1937.

Stairs to Dining / Theater Pavilion. Photographer: Sarah Robinson. 
The designer Rosan Bosch has also developed learning situations for young people with great care and consideration. Understanding the need for a variety of postures and gestures, her designs offer diverse experiences within a single space. These configurations: the mountaintop, campfire, cave, and water hole emphasize hands-on movement. The mountaintop establishes a place for individuals to express themselves before a group, in an elevated position that allows thoughts and ideas to flow from one person to many. The cave situation offers a protected place for individuals and very small groups to concentrate and reflect. The campfire is a space for group learning with attention directed centripetally and the water hole is situated along a circulation route, attracting a flow of passer-by to gather here. In this situation, students learn through spontaneous encounters, disruptions, and surprises. Movement in, and between, these situations emphasize the non-verbal dimension of communication and continually renew energy to keep learning fresh.

\section{Countermuscles}

Gaston Bachelard was also fond of using the image of the mollusk and the shell to evoke the deep reciprocity between the body and form and, in another provocative analogy, he called the road or path on which one walks a countermuscle to our muscles, $»$ it is as though the road itself had muscles or should I say counter muscles.«(Bachelard 1964: 11). Here too, the surfaces that support our footsteps are not passive and inert but actively resisting the force of our movements in an act of reciprocity and these repeated interactions are the way in which the places we inhabit work their way into our nerves and tissues - into our muscular consciousness. He goes on to say:

»The house we were born in is physically inscribed in us. It is a group of organic habits. After twenty years, in spite of all the other anonymous stairways, we would recapture the reflexes of the first stairway, we would not stumble on that rather high step. The house's entire being would open up, faithful to our own being. We would push the door that creaks with the same gesture, we would find our way in the dark in the distant attic. The feel of the tiny latch has remained in our hands." (Bachelard 1964: 14).

What he is suggesting here is that our bodily capabilities were exercised by the doors, stairs, and latches of our earliest years - that our bodies grew and 


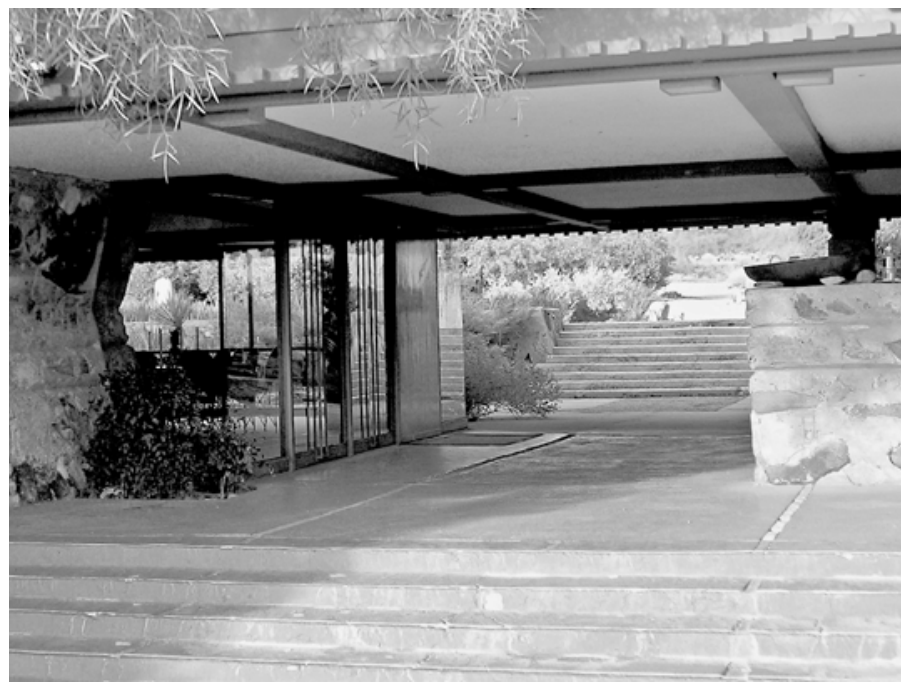

2.

Frank Lloyd Wright: Taliesin West, 1937.

Breezeway and Stairs. Photographer: Sarah Robinson. 
were shaped in correspondence with the possibilities and affordances of our environments, and given what we now know about the emotional import and cognitive consequences of certain gestures and postures, it would be difficult to overestimate the importance of careful design through all passages of life - but most importantly in our earliest, most vulnerable years.

Stairs are perhaps the most powerful »countermuscles« to shape our movements. The most sensitive attention to the rise and run ratio of stairs very concretely slows one's movements down or speeds them up. At Frank Lloyd Wright's Taliesin West where I lived for years, the treads were broad and the risers were shallow, forcing one to assume a slower gait. Walking at this pace and rhythm felt as though one were wearing a gown. Running on stairs of this proportion causes the most awkward movement, lacking in all elegance. Alvar Aalto employed the same strategy in his Viipuri library, where the supple linoleum stairs that lead to the reading room cushion the step while slowing one's gait, as is befitting of the quiet, reflective character of the activities meant to take place there. In both of these cases, calibrating individual movements in such specific concrete ways impacts the collective mood. In the first case, the stairs lead to the theater where festive formal events regularly occur. The stairs ever so subtly force one to assume a formal posture, priming one's mood for the social role that the theater was meant to fulfill. While in the latter case, the hushed and slowed walking extends a sense of courtesy to the atmosphere of quiet study collectively taking place in the space.

Again, while both Aalto and Wright were specific in the gestures the wanted to configure, like Aldo van Eyck, Herman Herzberger emphasizes the polyvalent use and meaning of his work. In his extended school in Arnhem, the Netherlands, for example, he designed a large set of wooden stairs with varying rises and runs to invite multiple uses and interpretations. In this way the stairs fulfill their utilitarian purpose, while going beyond it. The children study, read, play, and perform on these risers, as they are broad enough in places to lay and work upon. The open risers open myriad ways to crawl through and around them, the places below become intriguing hiding places, and their slightly offset diagonal layering subtly shifts and eases the need to march from one place to the next without noticing the possibilities of the in-between. And, like Bachelard's evocation of the »first stair» that lies dormant in the muscles, Herzberger remembers the pleasure of sitting on the softly rounded cornerstones in Amsterdam that he played on 78 years ago. The careful attention that went into making and placing those sculpted 


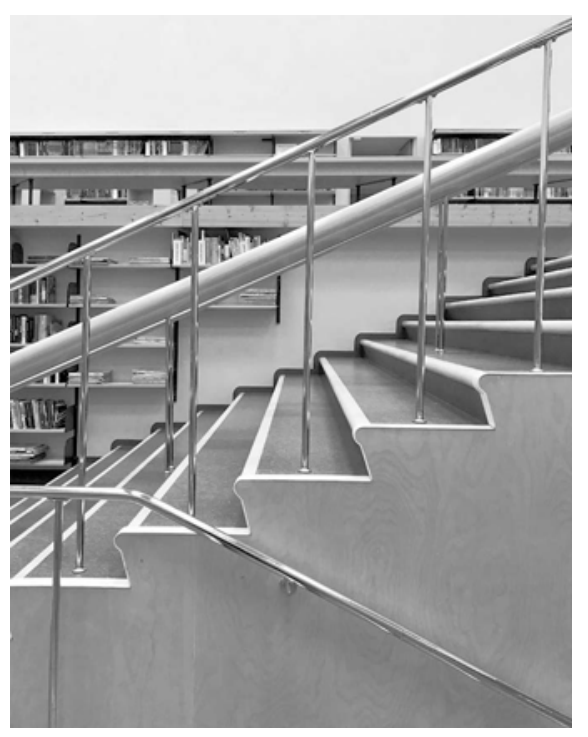

3. +4 .

Alvar Aalto: Viipuri Library, 1935. Stairs to Reading Area and Detail. Photographer: Sarah Robinson.

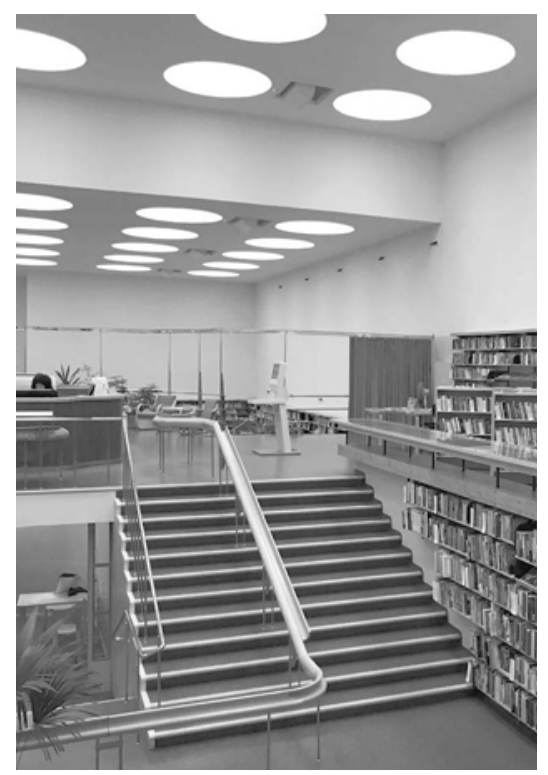


cornerstones remains in his muscular consciousness and no doubt shapes his designs to this day.

\section{From Emotion to Mood}

As we have seen with these various stairs, shifting our movements shifts our mood. While postures and gestures have very concrete physiological and psychological effects, larger scale movements can shift collective moods. While the words emotion and mood are often used interchangeably, the difference between them points to the way that moods can tend toward the collective more than emotions can. The primary difference is that emotions are sudden and tend to be fleeting, while moods tend to linger over longer periods of time. Emotions are discrete and readily expressed, while moods are vague and often difficult to name. Emotions are responses to specific situations, while moods are pervasive and slow - and while also situated, can linger beyond spatial boundaries. Emotion is closely tied with movement both etymologically and physiologically, while mood is a more diffuse affective state spread out over time. Mood is also closely tied to movement, but movement understood in a more subtle way. Rhythm is the kind of movement more clearly related to mood.

Rhythm was a central concern for John Dewey, who understood it to be a deep pattern in "the world of physical material and energies « (Dewey 1934: 151). He considered architecture to be as much of a rhythmic art as music and insisted that »denial of rhythm to pictures, edifices, and statues, or the assertion that it is found in them metaphorically, rests upon ignorance of the inherent nature of every perception « (Dewey 1934: 180). Dewey anticipated what we now know about perception by five decades: perception is rhythmic. Not only does the auditory system operate according to rhythmic vibrations - visual, touch, taste, and proprioceptive systems are rhythmic as well. They sample the world in quanta or packets like the saccadic movements of vision, and because the brain is rhythmic, repetitive patterns of neural activity can be measured and understood in terms of resonance and oscillating waves. We live in a sea of rhythm from the human heartbeat to the circadian rhythms that connect us to the cycles of light on a rotating planet. All of our experience is rhythmic and these movements from micro to macro scale introduce a critical, if little understood, temporal dimension into architectural experience. 
In his classic Experiencing Architecture, Steen Eiler Rasmussen dedicated a chapter to rhythm, and like Dewey, understood rhythm as a feature of the natural world - of oscillating energy between tension and release. In terms of architecture, he understood rhythm to be »subtle variations within strict regularity« (Rasmussen 1959: 127). Yet he also discusses rhythm in terms of bodily movement and mood. Physical work, for example, becomes more enjoyable and easier when the movements involved are regularly alternated:

»There is something mysterious about the stimulating effect of rhythm. You can explain what it is that creates rhythm but you have to experience it yourself to know what it is like. [...] A man who moves rhythmically starts the motion himself and feels that he controls it. But very shortly, the rhythm controls him; he is possessed by it. It carries him along. Rhythmic motion gives a feeling of heightened energy« (ibid.: 134).

Rasmussen also points out that those who move in the same way collectively share rhythms. Clothing from earlier eras that now seems cumbersome and limiting was once worn with great ease because the people in those cultural milieus moved to different rhythms. Architecture in various periods can also be understood in terms of the expression of changing rhythms. Here, the Spanish Steps in Rome provide a classic example. The functional role of the staircase was to connect the low-lying Piazza di Spagna with the Piazza della Trinità above and the more obvious solution would have been to build long, straight monumental stairs, such as those that lead to the Piazza del Campidoglio. The Spanish Steps however, with their rhythmic bends and curves, were not only designed to walk upon, as much as they were made to dance upon. They were built during the period when the Baroque waltz, the Polonaise, was in high fashion. In the choreography for the Polonaise, the dancers advance four by four in a line and then divide, two going to the right and two to the left, then turning, curtsying, and meeting back on the large landing, then repeating these movements. Imagine gradually waltzing one's way up to the uppermost terrace and elegantly turning to face the panorama of Rome lying at one's feet. The Spanish Steps concretize an altogether different rhythm than the contemporary rhythms to which we have now grown accustomed: »We can see a petrification of the dancing rhythm of a period of gallantry; it gives an inkling of something that was, something our generation will never know « (Rasmussen 1959:136). Moving together engages shared rhythms that coincide with shared moods. We know from research in 
the psychology of musical experience that people who move together during a live musical performance experience higher levels of interpersonal coordination and cooperation (Dotov et al. 2021). Neuroscientists at the University of Parma also found that audience members in a concert experience cardiac synchrony regardless of whether they are strangers or not (Ardizzi et al. 2020). We entrain with movements whether or not their source is living or non-living. Entrainment is a process where the frequency of energy, from two or more systems, tends to synchronize through a process of mutual influence as one adapts to the other. The closely related phenomenon of resonance refers to the transfer of energy from systems vibrating at the same or similar frequencies. A familiar example is when a tuning fork transfers its vibration to a string on a musical instrument tuned to the same frequency, or when a vocalist shatters a glass by matching the frequency of the crystal from which it is made. Yet, as it was mentioned earlier with rhythm, resonance and entrainment apply to non-sonic phenomena as well. Non-linear couplings between the brain, body, and environmental oscillations have been studied in terms of cognitive, perceptual, autonomic, physiological, motor, and social entrainment (Trost/Vuilleumier 2013; Vara Sánchez 2021). The tendency toward entrainment is shared across cultures, taxonomies, and species, and because the processes of entrainment and resonance are features of the animate and inanimate material world they point to a way to understand the potentials of architecture and human interaction.

The complex and daunting mandate to provide "perpetual homecoming" is overwhelming in its complexity. Yet, when we begin this task by taking the capacities and potentials of the body seriously, new horizons of possibility begin to present themselves. Everything we make has untold dimensions and starting with the movements of the body is far from mundane. An entire cosmology is contained in the words, »stand up straight! « as Pierre Bourdieu insisted (Bell 1992: 141). When we consider that every gesture elicits a cascade of oscillatory, hormonal, muscular, psychological, and cognitive effects, one can begin to get an inkling of what is meant by those words. Our movements and the very expressive possibilities of our bodies are always conditioned by, and respond to, a specific context. The contexts that designers and architects are responsible for creating, exercise the muscular repertoire, reinforce and modulate moods and emotions, and instill cultural habits and attitudes for generations of people who inhabit our work. 
References

Adelmann, Pamela K./Zajonc, Robert B. (1989): »Facial Efference and the Experience of Emotion«, in: Annual Review of Psychology 40, 249-280.

Ardizzi, Martina/Calbi, Marta/Tavaglione, Simona/Umiltà, Maria Alessandra/Gallese, Vittorio (2020): »Audience Spontaneous Entrainment During the Collective Enjoyment of Live Performances: Physiological and Behavioral Measurements«, in: Nature Scientific Reports 10, 3813.

Bachelard, Gaston [1958]: La Poétique de l'Espace, Paris: Presses Universitaires de France-English translation The Poetics of Space, New York: Orion, 1964.

Bell, Catherine (1992): Ritual Theory, Ritual Practice, Oxford: Oxford University Press.

Carney, Dana R./Cuddy, Amy J./Yap, Andy ]. (2010): »Power Posing: Brief Nonverbal Displays Affect Neuroendocrine Levels

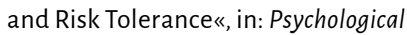
Science 10/21,1363-1368.

Darwin, Charles (1872): The Expression of Emotions in Man and Animals, London: John Murray.

Dewey, John (1934): Art as Experience, New York: Minton, Balch \& Company.

Dimberg, Ulf/Söderkvist, Sven (2011): »Facial Feedback«, in: Journal of Nonverbal Behavior 35, 17-33.

Dotov, Dobromir/Bosnyak, Daniel/ Trainor, Laurel ]. (2021): „Collective Music Listening: Movement Energy is Enhanced by Groove and Visual Social Cues «, in: Experimental Psychology 6/74,1037-1053.

Ekman, Paul/Davidson, Richard (1993): »Voluntary Smiling Changes Regional Brain Activity«, in: Psychological Science 4/5, 342-345.

Hirshfield, Jane (1997): Nine Gates: Entering the Mind of Poetry, New York: Harper Collins.
Inagaki, Kazuki/Takeshi, Shimizu/ Yosuke, Sakairi (2018): »Effects of Posture Regulation on Mood States, Heart Rate and Test Performance in Children «, in: Educational Psychology 38/9, 1129-1146.

Johnson, Mark (2015): »The Embodied Meaning of Architecture «, in Sarah Robinson and Juhani Pallasmaa, (eds.), Mind in Architecture: Neuroscience,

Embodiment and the Future of Design, Cambridge, MA: The MIT Press.

Lewis, Michael B. (2012): »Exploring the Positive and Negative Implications of Facial Feedback«, in: Emotion 12/4, 852-859.

McCarter, Robert (2015): Aldo Van Eyck, New Haven: Yale University Press.

Merleau-Ponty, Maurice [1945]:

Phénoménologie de la perception. - English translation [1962]: Phenomenology of Perception, London: Routledge, 2002.

Michalak, Johannes/Mischnat, Judith/ Teismann, Tobias (2014): »Sitting Posture Makes a Difference-Embodiment Effects on Depressive Memory Bias«, in: Clinical Psychology and Psychotherapy 21/6, 519-524.

Oosterwijk, Suzanne/Rotteveel, Mark/ Fischer, Agneta H./Hess, Ursula (2009): «Embodied Emotion Concepts: How Generating Words about Pride and Disappointment Influences Posture «, in: European Journal of Social Psychology 39, 457-466.

Rasmussen, Steen Eiler (1959): Experiencing Architecture, Cambridge, MA: The MIT Press.

Riskind, John H./Gotay, Carolyn C. (1982): »Physical Posture: Could It Have Regulatory or Feedback Effects on Motivation and Emotion«, in: Motivation and Emotion 6, 273-298.

Riskind, John H. (1984): »They Stoop to Conquer: Guiding and Self-Regulatory Functions of Physical Posture after Success and Failure «, in: Journal of Personality and Social Psychology 47/3, 479-493. 
Robinson, Sarah (2021): Architecture is a Verb, London: Routledge.

Stepper, Sabine/Strack, Fritz (1993): »Proprioceptive Determinants of Emotional and Nonemotional Feelings«, in: Journal of Personality and Social Psychology 64/2, 211-220.

Trost, Wiebke Johanne/Vuilleumier, Patrick (2013): »Rhythmic Entrainment as a Mechanism for Emotion Induction by Music«, in Tom Cochrane/Bernadino Fantini/ Klaus R. Scherer, The Emotional Power of Music: Multidisciplinary Perspectives on Musical Arousal, Expression, and Social Control, Oxford: Oxford University Press.

Vara Sánchez, Carlos (2021): »Enacting the Aesthetic: A Model for Raw Cognitive Dynamics«, in: Phenomenology and the Cognitive Sciences, doi: 10.1007/ s11097-021-09737-y

Veenstra, Lotte/Schneider, Iris/ Koole, Sander L. (2017): »Embodied Mood Regulation: The Impact of Body Posture on Mood Recovery, Negative Thoughts, and Mood-Congruent Recall«, in: Cognition and Emotion 31/7, 1361-1376. 
